\title{
SUSTAINABLE DEVELOPMENT IN ENGLISH PLANNING POLICY: A LAWYER'S PERSPECTIVE
}

\author{
CONSTANZE LOWRISON BELL \\ Kings' Chambers, Manchester, UK
}

\begin{abstract}
This paper argues that underlying the debate regarding the correct interpretation of and approach to the 'presumption in favour of sustainable development' in the National Planning Policy Framework are two more fundamental clashes. First, a clash between the role of lawyers and policy experts in environmental decision making; and second, confusion regarding whether sustainable development is intended to be an outcome of policy compliance or, some other, more amorphous concept.

Keywords: sustainable development policy, NPPF, presumption in favour of sustainable development.
\end{abstract}

\section{INTRODUCTION}

In the UK it is settled law that the interpretation of planning policy is a matter of law and the application of planning policy is a matter of judgment for the decision-maker [1]. However, this position is not without difficulties.

The National Planning Policy Framework ('NPPF' or 'the Framework') sets out the UK Government's planning policies for England. A new, revised Framework was released in July 2018 [2].

The argument here is that the increased role of lawyers in environmental decision making and a policy process orientated approach to sustainable development has robbed the concept of meaning in the UK planning system.

This paper examines how the UK courts have construed UK Government policy regarding the 'presumption in favour of sustainable development' as set out in the Framework.

\section{THE NATIONAL PLANNING POLICY FRAMEWORK}

On 24 July 2018 the UK Government's Ministry of Housing, Communities and Local Government ('MHCLG') published a revised Framework ('the revised Framework'), replacing the first version of the Framework which was published in March 2012 ('the old Framework') [3]. Chapter 2 of the old Framework and the revised Framework are both titled 'Achieving Sustainable Development'. Both Frameworks state that 'the purpose of the planning system is to contribute to the achievement of sustainable development'. From 2004 the stated purpose of planning in Britain in legislation has been to 'contribute to the achievement of sustainable development' [4].

Planning law requires that applications for planning permission (or, to be precise, 'determinations under the Planning Acts') be determined in accordance with the development plan (which is comprised of Local and neighbourhood plans and, where relevant, the London Plan), unless material considerations indicate otherwise [5]. The Framework must be taken into account in preparing the development plan and is a material consideration in planning decisions. Paragraph 12 of the revised Framework specifically acknowledges this noting that 'the presumption in favour of sustainable development does not change the statutory status of the development plan as the starting point for decision making. Where a planning application conflicts with an up-to-date development plan (including any neighbourhood plans that form part of the development plan), permission should not usually be granted. Local planning authorities may take decisions that depart from an up-to-date development 
plan, but only if material considerations in a particular case indicate that the plan should not be followed'. It follows that in policy terms there is a presumption in favour of refusal when there is conflict with the development plan; the starting point is adverse to the grant of development.

\subsection{Sustainable development policy in the old Framework and revised} Framework compared

The old Framework (at paragraph 6) advised that the policies in paragraphs 18 to 219 of NPPF, taken as a whole, constitute the Government's view of what sustainable development in England means in practice for the planning system. The revised Framework omits this sentence entirely. It is submitted that this sentence has been omitted to avoid confusion about the nature of the exercise to determine whether development proposals constitute sustainable development. It would, it is submitted, be very odd if the Government did not consider its policy statement to guide the achievement of sustainable development given the purpose of the planning system as established in statute.

The revised Framework avoids defining sustainable development as being comprised of three dimensions. Instead it prefers to comment in broad terms, noting that 'at a high level, the objective of sustainable development can be summarised as meeting the needs of the present generation without compromising the ability of future generations to meet their own needs' (at paragraph 7).

The old Framework was commendably direct: 'There are three dimensions to sustainable development: economic, social and environmental' (at paragraph 7). The text continued 'These dimensions give rise to the need for the planning system to perform a number of roles', three roles were then identified: economic, social and environmental. These roles were held to be 'mutually dependent' (at paragraph 8) and it was stated that 'to achieve sustainable development, economic, social and environmental gains should be sought jointly and simultaneously through the planning system'.

Both Frameworks recognise that economic, social and environmental factors play a role in sustainable development but approach this issue in slightly different ways.

The revised Framework observes that "Achieving sustainable development means that the planning system has three overarching objectives, which are interdependent and need to be pursued in mutually supportive ways (so that opportunities can be taken to secure net gains across each of the different objectives)' (at paragraph 8). These three objectives are identified as economic, social and environmental objectives. In terms of delivering these objectives, the revised Framework is express: 'These objectives should be delivered through the preparation and implementation of plans and the application of the policies in this Framework; they are not criteria against which every decision can or should be judged'.

It is submitted that this redraft indicates a new direction for the achievement of sustainable development. Achieving sustainable development is to be done by pursuing objectives within the context of preparing local plan policies and the application of Framework policies. It is an outcome of policy application. This is a very different from and, it is submitted, a much more remote idea than seeking gains which are a composite part of the definition of sustainable development within the planning system as a whole. The latter approach, as set out in the old Framework, suggested that the question of whether or not development was sustainable development could be asked at any stage of the planning process and answered with reference to Framework policies in a distinct exercise. For example, a decision maker could ask if the proposal represented sustainable development by considering the proposal against the three dimensions of sustainable development. 


\section{THE PRESUMPTION IN FAVOUR OF SUSTAINABLE DEVELOPMENT}

The old Framework, at paragraph 14, advised that the 'presumption in favour of sustainable development' ('the presumption') should be seen as 'a golden thread running through both plan-making and decision-taking'. The reference to a 'golden thread' has been removed in the revised Framework.

Paragraph 10 of the revised Framework addresses the presumption in the following terms: 'So that sustainable development is pursued in a positive way, at the heart of the Framework is a presumption in favour of sustainable development (at paragraph 11)'. The presumption may be 'at the heart of the Framework' but it seems that it is found (seemingly only) 'at paragraph 11'. Fig. 1 is the revised Framework's paragraph 11 setting out the presumption (emphasis in the original text).

\subsection{The Court of Appeal Decision in Barwood Strategic Land II}

In Barwood Strategic Land II [6] the Court of Appeal considered the true meaning and scope of government policy for the 'presumption in favour of sustainable development'. The Court of Appeal's reasoning was based on paragraph 14 of the old Framework (now paragraph 11 in the revised Framework).

The court noted that whilst the interpretation of planning policy was a matter of law for the court, planning policies are not statutory or contractual provisions and should not be construed as if they were. Statements of policy are to be interpreted objectively by the court in accordance with the language used and in its proper context. A failure to properly understand or apply relevant policy would constitute a failure to have regard to a material consideration or will amount to having regard to an immaterial consideration so as to constitute an error of law. The application of policy is an exercise in planning judgment for the decision maker and is not a role for the court.

In Barwood Strategic Land II the Local Planning Authority had honoured its statutory and policy obligations to have in place an up-to-date local plan (a development plan document) and have a five-year supply of deliverable housing sites.

The Court of Appeal had to consider two contradictory High Court judgments. In Wychavon District Council [7] Coulson J held that the presumption in favour of sustainable development did exist outside of paragraph 14 of the old Framework. The presumption was not defined in paragraph 14; paragraph 14 explained the effect of the presumption. As sustainable development was the golden thread throughout the Framework, it could not be right to say that the presumption would only apply where the development plan was absent, silent or relevant policies were out of date. In Cheshire East Borough Council [8] Jay J rejected the notion that the old Framework required a 'freewheeling exercise of discretion without parameters' to determine whether or not a proposal was sustainable development. He held that the concept of sustainable development involved the striking of a balance between different considerations which may way in favour of, or against, a grant of planning permission. The Government's policy regarding how that balance is to be struck was to be found at paragraph 14 (of the old Framework) and only at paragraph 14.

In a further High Court decision, Trustees of the Barker Mills Estates [9], Holgate J noted that as the presumption applied where a proposal accords with the development plan, the developer/applicant gets the benefit of the presumption under paragraph 14 and the statutory presumption under which development decisions should be made in accordance with the development plan. Holgate $\mathrm{J}$ did not consider that the approach in Wychavon was supported by the Framework or by case law. 
11. Plans and decisions should apply a presumption in favour of sustainable development.

For plan-making this means that:

a) plans should positively seek opportunities to meet the development needs of their area, and be sufficiently flexible to adapt to rapid change;

b) strategic policies should, as a minimum, provide for objectively assessed needs for housing and other uses, as well as any needs that cannot be met within neighbouring areas $\left[5^{*}\right]$, unless:

i. the application of policies in this Framework that protect areas or assets of particular importance provides a strong reason for restricting the overall scale, type or distribution of development in the plan area [6*]; or

ii. any adverse impacts of doing so would significantly and demonstrably outweigh the benefits, when assessed against the policies in this Framework taken as a whole.

For decision-taking this means:

c) approving development proposals that accord with an up-to-date development plan without delay; or

d) where there are no relevant development plan policies, or the policies which are most important for determining the application are out-of-date [7*], granting permission unless:

i. the application of policies in this Framework that protect areas or assets of particular importance provides a clear reason for refusing the development proposed $\left[6^{*}\right]$; or

ii. any adverse impacts of doing so would significantly and demonstrably outweigh the benefits, when assessed against the policies in this Framework taken as a whole.

[5*] As established through statements of common ground (see paragraph 27).

[6*] The policies referred to are those in this Framework (rather than those in development plans) relating to: habitats sites (and those sites listed in paragraph 176) and/or designated as Sites of Special Scientific Interest; land designated as Green Belt, Local Green Space, an Area of Outstanding Natural Beauty, a National Park (or within the Broads Authority) or defined as Heritage Coast; irreplaceable habitats; designated heritage assets (and other heritage assets of archaeological interest referred to in footnote 63); and areas at risk of flooding or coastal change.

[7*] This includes, for applications involving the provision of housing, situations where the local planning authority cannot demonstrate a five-year supply of deliverable housing sites (with the appropriate buffer, as set out in paragraph 73); or where the Housing Delivery Test indicates that the delivery of housing was substantially below (less than $75 \%$ of) the housing requirement over the previous three years. Transitional arrangements for the Housing Delivery Test are set out in Annex 1.

Figure 1: Paragraph 11 of the revised National Planning Policy Framework [1]. 
Crucially, Holgate $\mathrm{J}$ drew a distinction between defining what might amount to sustainable development and defining the circumstances in which a presumption in favour of sustainable development would arise and held that it was erroneous to conflate the two. The court determined that 'it is only that paragraph (paragraph 14 of the old Framework) which identifies the circumstances in which the presumption arises'.

In Barwood Strategic Land II the Court of Appeal endorsed the analysis of Holgate $J$ and added some further observations. Firstly, the court noted that the "presumption in favour of sustainable development' is a presumption of planning policy and is an exercise in judgment within the overall exercise required by stature, namely that a determination under the planning Acts should be in accordance with the development plan unless material considerations indicate otherwise. Secondly, the court noted that the presumption existed in paragraph 14 only and nowhere else. Paragraph 14 was clear and complete regarding the circumstances in which and way in which, it is intended to operate. Thirdly, a development may not benefit from the presumption and yet be granted planning permission and, on the contrary, a development may benefit from the presumption and yet be found unacceptable. The presumption is a rebuttable, not irrebuttable, presumption. These will be matters of judgment for the decision maker.

\subsection{The presumption in the revised Framework}

The revised Framework is drafted so as to make clear that the presumption exists only within the context of paragraph 11. There is to be no 'freewheeling exercise of discretion' not even within the parameters of the three overarching directives which are now objectives integral to developing policy and applying framework policy rather than core dimensions of sustainable development.

Since the role of the planning system is to contribute to the achievement of sustainable development and plan-making incorporates the application of the presumption (albeit in a slightly different form) it is perhaps wholly unsurprising that the first limb of the presumption in a decision taking context should be a command to approve proposals that accord with the development plan 'without delay'. This part of the presumption is, perhaps, a broad restatement of the statutory requirement and seemingly rests on the premise that sustainable development will have informed the drafting of development plan policy.

The second limb is more interesting. The decision maker is tasked firstly with identifying whether there are relevant development plan policies before considering whether the policies which are 'the most important for determining the application' are out-of-date. If either of these two considerations is borne out, then planning permission should be granted unless one of two exceptions is met. Paragraph 213 of the revised Framework clarifies that existing policies 'should not be considered out-of-date simply because they were adopted or made prior to the publication of this Framework. Due weight should be given to them, according to their degree of consistency with this Framework'. It is unclear why the absence or 'outdated' nature of a policy should entail the conclusion that the proposal constitutes sustainable development benefiting from the presumption such that planning permission should be granted. The absence or ineffectiveness of policy does not obviously bear on the question of whether the proposed development honours the principle of meeting the needs of the present generation without compromising the ability of future generations to meet their own needs (at paragraph 7 of the revised Framework). If the pursuit of sustainable development means achieving certain objectives which ought to have been captured in policy but manifestly have not been (because there are no policies, or they are out of date), then it is still less clear that 
the proposal would represent sustainable development. On the contrary there might be a policy reason to have a presumption in favour of development where development plans are silent or out of date, so as to motivate Local Planning Authorities to produce and maintain up to date development plan documents.

If there is to be no discretionary judgment exercise to establish whether the proposal is sustainable then the decision maker is prevented from embarking on a separate assessment of sustainability. Bound by the confines of paragraph 11 and unable to step outside it, the decision maker must accept that the application of paragraph 11 will establish whether or not the proposal benefits from the presumption.

It seems almost too obvious to state that a proposal that benefits from the presumption must surely constitute sustainable development. Yet the courts have endorsed a distinction between whether or not a proposal is sustainable development and whether it should benefit from the presumption. It is therefore entirely possible that a proposal could be sustainable development and not benefit from the presumption or, conversely benefit from the presumption and yet not constitute sustainable development. Whether this will in fact occur turns on the efficacy of paragraph 11 as a 'sift' to establish what does or does not benefit from the presumption. The difficult in judging the efficacy of this sift is attributable, it is submitted, to the revised Framework's movement further away from a clear definition of sustainable development.

The second exception requires identification of adverse impacts and a weighting exercise. This weighting exercise is often described as 'the tilted balance' because the balance is tipped in favour of development: to fail the balancing exercise adverse impacts must not only outweigh the benefits of the development but must 'significantly and demonstrably' outweigh the benefits. In some respects, the second exception is a classic example of 'weak' sustainability: assets may be consumed or sacrificed if the overall benefit would be positive. However, the overall benefit here might be marginal or even outweighed by the adverse impacts. It would be open to a decision maker to find that this exception was not engaged because whilst the adverse impacts outweighed the benefits they did not do so 'significantly and demonstrably'. The focus of the exception is on quantifying the adverse impacts rather than the benefits. The bar is set high.

The first exception is closer to what might commonly be understood as 'strong' sustainability [10]. It is concerned with the protection of assets and areas, an avoidance of loss and possibly a recognition that certain types of loss cannot be adequately replaced by compensatory benefits. The wording of this exception has changed. Under the old Framework the exception was in much more direct, succinct terms and simply read: 'specific policies in this Framework indicate development should be restricted'. It is submitted that the revised Framework dilutes this exception, incorporating a balancing exercise into the policy by requiring that the application of restrictive Framework policies 'provide a clear reason for refusing the development proposed'. This addition is, at first blush, an odd addition. It might quite reasonably be expected that the application of a restrictive Framework policy would in and of itself provide a clear reason for refusal. Thus, the starting point would surely be that the restrictive policy provided a clear reason for refusal. However, this addition adds an element of uncertainty. What ultimately constitutes a 'clear reason' will undoubtedly be a matter of planning judgment for the decision maker and as such immune from legal challenge, (save in circumstances where the decision is irrational or discloses some other error of public law). It remains to be seen how this policy is applied in practice, but it is submitted that there is now scope to go behind restrictive policies and argue about their merits or justification in a specific case. 
Cumulatively, the two exceptions indicate that Government policy has moved towards a weaker and much less clear notion of sustainable development.

\section{CONCLUSION}

The judgment in Barwood Strategic Land II and the revised Framework prevent the decision maker from embarking on an independent assessment of sustainable development. The revised Framework, in its coyness concerning what defines sustainable development, does little to elucidate the concept and perhaps assists less than the old Framework in providing a working definition. This is likely deliberate and an attempt to discourage discretionary exercises of judgment regarding sustainability outside the confines of the presumption. The revised Framework, it is submitted, firmly pursues the idea of sustainable development as an outcome of policy compliance and is overly mechanical.

The courts have repeatedly warned that lawyers should not unnecessarily interfere in the process of planning decision making. Lindblom LJ observed in Barwood Strategic Land II (at paragraph 50), '[...] The court should always resist over-complication of concepts that are basically simple. Planning decision-making is far from being a mechanical, or quasimathematical activity. It is essentially a flexible process, not rigid or formulaic. It involves, largely, an exercise of planning judgment, in which the decision-maker must understand relevant national and local policy correctly and apply it lawfully to the particular facts and circumstances of the case in hand, in accordance with the requirements of the statutory scheme. The duties imposed by section 70(2) of the 1990 Act and section 38(6) of the 2004 Act leave with the decision-maker a wide discretion. The making of a planning decision is, therefore, quite different from the adjudication by a court on an issue of law...'.

It is submitted that the disjunctive approach to sustainable development in which the presumption and the definition of sustainable development are treated as distinct concepts invites lawyers into a space that ought properly to be occupied by planning consultants and other decision makers.

[1] Tesco Stores Limited v Dundee City Council (Scotland) [2012] UKSC 13, [2012] PTSR 983.

[2] Ministry of Housing, Communities and Local Government, National Planning Policy Framework. www.gov.uk/government/collections/revised-national-planning-policyframework\#revised-national-planning-policy-framework. Accessed on: 24 Jul. 2018.

[3] Ministry of Housing, Communities and Local Government, National Planning Policy Framework. http://webarchive.nationalarchives.gov.uk/20180608095821/ https://www.gov.uk/government/publications/national-planning-policy-framework-2. Accessed on: 31 Jul. 2018.

[4] Planning and Compulsory Purchase Act 2004, s 39.

[5] Planning and Compulsory Purchase Act 2004, s 38 (6).

[6] Barwood Strategic Land II v East Staffordshire Borough Council and Secretary of State for Communities and Local Government [2017] EWCA Civ 893, [2018] P.T.S.R. 88.

[7] Wychavon District Council v Secretary of State for Communities and Local Government [2016] EWHC 592 (Admin), [2016] P.T.S.R. 675.

[8] Cheshire East Borough Council v Secretary of State for Communities and Local Government [2016] EWHC 571 (Admin), [2016] PTSR 1052. 
72 Sustainable Development and Planning X

[9] Trustees of the Barker Mills Estates v Test Valley Borough Council [2016] EWHC 3028 (Admin), [2017] PTSR 408.

[10] Jacobs, M., Sustainable development as a contested concept. Fairness and Futurity. Essays on Environmental Sustainability and Social Justice, ed. A. Dobson, Oxford University Press: Oxford, pp. 21-45, 1999. 